\title{
OPEN The influence of breeding history, origin and growth type on population structure of barley as revealed by SSR markers
}

\author{
Seyyed Abolghasem Mohammadi ${ }^{1,2,3 凶}$, Nayyer Abdollahi Sisi ${ }^{1}$ \& Behzad Sadeghzadeh ${ }^{4}$
}

Natural and mass selection during domestication and cultivation favored particular traits of interest in barley. In the present study, population structure, and genetic relationships among 144 accessions of barley landraces and breeding materials from various countries were studied using a set of 77 and 72 EST-SSR and gSSR markers, respectively distributed on seven chromosomes of barley. In total, 262 and 429 alleles were amplified in 77 EST-SSRs and 72 gSSR loci, respectively. Out of which, 185 private/group-specific alleles were identified in the landraces compared with 14 in "cultivar and advanced breeding lines", indicating the possibility to introgress favorite alleles from landraces into breeding materials. Comparative analysis of genetic variation among breeding materials, Iranian landraces, and exotic landraces revealed higher genetic diversity in Iranian landraces compared with others. A total of 37, 15, and 14 private/group-specific alleles were identified in Iranian landraces, exotic landraces, and breeding materials, respectively. The most likely groups for 144 barley genotypes were three as inferred using model- and distance-based clustering as well as principal coordinate analysis which assigned the landraces and breeding materials into separate groups. The distribution of alleles was found to be correlated with population structure, domestication history and eco-geographical factors. The high allelic richness in the studied set of barley genotype provides insights into the available diversity and allows the construction of core groups based on maximizing allelic diversity for use in barley breeding programs.

Barley is one of the oldest known domesticated crops with a large genome and a high number of varieties and accessions worldwide. Archaeological and molecular studies indicate that it was domesticated from two-row wild barley Hordeum vulgare L. subsp. spontaneum in the Near East about 10,000 years ago ${ }^{1-3}$. Due to the wide adaptation of barley to various environmental conditions, its germplasm pool with high genetic diversity has the potential to breed for adaptation to different environmental conditions. However, genetic diversity in modern barley cultivars has been declined following intense selection in modern plant breeding programs. Therefore, characterization and the use of barley germplasm arrays such as landraces are essential for identifying candidate genes for important traits ${ }^{4-6}$.

Domestication and human selection in subsistence agriculture over a long period resulted in the development and evolution of landraces with high adaptation to the local natural environments. In such systems, natural selection, seed exchange, and human migration generated a huge genetic variation which has been maintained by farmers ${ }^{7,8}$. Due to heterogeneous nature of the landraces, huge genetic diversity is structured at the field and farmer levels (between and within populations). Morphological and agronomic traits, as well as molecular tools, have been utilized to assess components of the genetic diversity in landraces ${ }^{9,10}$.

Modern plant breeding activities in the recent century resulted in the development of a large number of elite varieties with a higher yield, better quality, and resistance to stresses, but the narrow genetic background ${ }^{11}$. Replacement of highly adapted landraces by modern varieties performing under optimal conditions but failing under harsh environments ${ }^{12}$ resulted in the disappearance of most landraces of crop plants from practical farming ${ }^{11,13}$. Although in many countries, landraces were completely replaced by modern varieties starting from a long time back, in some marginal areas, to take advantage of the specific adaptations of landraces to

${ }^{1}$ Department of Plant Breeding and Biotechnology, Faculty of Agriculture, University of Tabriz, 51666 Tabriz, Iran. ${ }^{2}$ Center of Excellence in Cereal Molecular Breeding, University of Tabriz, 51666 Tabriz, Iran. ${ }^{3}$ Center for Cell Pathology, Department of Life Sciences, Khazar University, Baku AZ1096, Azerbaijan. ${ }^{4}$ Dryland Research Institute of Iran, Maragheh, Iran. ${ }^{\circledR}$ email: mohammadi@tabrizu.ac.ir 


\begin{tabular}{|l|l|l|l|l|l|}
\hline Chromosome & Number of markers & Length $(\mathbf{c M})$ & Interval spanned $(\mathbf{c M})$ & Mean number of alleles & PIC \\
\hline $1 \mathrm{H}$ & 20 & 125.89 & 6.29 & 4.90 & 0.48 \\
\hline $2 \mathrm{H}$ & 26 & 161.48 & 6.21 & 3.81 & 0.44 \\
\hline $3 \mathrm{H}$ & 19 & 137.70 & 8.10 & 4.84 & 0.57 \\
\hline $4 \mathrm{H}$ & 23 & 133.40 & 5.80 & 6.04 & 0.62 \\
\hline $5 \mathrm{H}$ & 23 & 166.40 & 7.56 & 3.69 & 0.46 \\
\hline $6 \mathrm{H}$ & 15 & 121.56 & 8.10 & 4.80 & 0.51 \\
\hline $7 \mathrm{H}$ & 20 & 152.60 & 7.63 & 4.90 & 0.48 \\
\hline Total & 146 & 999.03 & 6.93 & 4.65 & 0.51 \\
\hline
\end{tabular}

Table 1. Markers distribution and statistics concerning the selected genomic region. PIC polymorphic information content.

the agro-ecosystem, their cultivation still continues ${ }^{14}$. The landraces of self-pollinated species such as barley harboring the chromosomal regions consisted of blocks of genes with a low frequency of recombination which may confer a specific adaptation to specific environments $s^{15}$. This shows that the landraces are ideal association panels to identify genes controlling adaptive traits in crop species ${ }^{10,16}$. Therefore, for efficient utilization of barley landraces in breeding programs and to develop the strategies for their optimal conservation, it is necessary systematically to evaluate molecular diversity encompassed in the landraces collections ${ }^{17}$. Among the DNA markers, SSR markers have been extensively use to analyze population structure and genetic diversity in barley germplasm, due to the high polymorphism, reproducibility, co-dominant and multi-allelic nature when compared to most of the marker systems ${ }^{16-22}$.

The present study was carried out to (i) characterize the allelic diversity, and population structure in a collection of 119 barley landraces from Iran and across the world including two-row and six-row types with different growth habits and compared with those of barley cultivars and advanced breeding lines and (ii) compare the efficiency of genomic and EST- SSR markers in assessing genetic relationships and population structure.

\section{Results}

Allelic variation of EST-SSRs and genomic SSRs. Genetic relationships in a set of 144 barley genotypes were investigated using $72 \mathrm{gSSR}$ and 77 EST-SSR loci distributed at seven barley chromosomes. The interval spanning between markers used varied from $5.80 \mathrm{cM}$ in $4 \mathrm{H}$ to $8.10 \mathrm{cM}$ in $6 \mathrm{H}$ with an average of $6.93 \mathrm{cM}$. The number of alleles/locus varied from $3.69(5 \mathrm{H})$ to $6.04(4 \mathrm{H})$ and PIC ranged from $0.44(2 \mathrm{H})$ to $0.62(4 \mathrm{H})$ (Table 1). The used SSR markers were selected based on technical reliability, polymorphism, and their distribution in the barley genome. Description of the EST-SRR and gSSR loci and their chromosome location are presented in Tables 2 and 3, respectively. A wide range of genetic diversity was detected in the panel of studied barley genotypes by gSSRs compared with EST-SSRs as revealed by a number of alleles $(\mathrm{Na})$, number of effective alleles (Ne), Shannon's index (I), expected heterozygosity (He) and polymorphic information content (PIC). The 77 EST-SSRs detected 262 alleles in the studied genotypes, compared to 429 alleles for gSSRs. For EST-SSR, the number of alleles varied from 2 to 9 (SCSSR9398 on $6 \mathrm{H}$ ) with a mean value of $3.40 \pm 0.18$ alleles/locus. The number of alleles amplified by gSSR primer pair was significantly higher and 429 alleles were amplified at 72 gSSR loci. The number of alleles varied from 2 to 15 (Bmac32 on $1 \mathrm{H}$ ) with a mean value of $5.96 \pm 0.34$ alleles/ locus. Out of 77 EST-SSR, 25 amplified a low number of alleles (2 alleles) compared with 11 of the gSSRs. Seventeen of the EST-SSRs amplified the relatively high number of alleles (5-9) compared with 43 of the gSSRs. The mean of effective number of alleles was $2.28 \pm 0.12$ with a range of 1.09 (GBM1404) to 7.00 (SCSRR9398) and $3.83 \pm 0.23$ with a range of 1.12 (EBmac659) to 10.65 (EBmac788) for EST-SSRs and gSSRs, respectively. Shannon's index ranged from 0.18 (GBM1404) to 2.05 (SCSRR9398) with an average of $0.87 \pm 0.05$ for the EST-SSRs compared to 0.21 (EBmac659) to 2.67 (Bmac40) with a mean value of $1.32 \pm 0.06$ for the gSSRs. A wide range of He and PIC values was observed in the set of gSSR compared with EST-SSR. The 72 SSRs had an average He and PIC of $0.63 \pm 0.02$ and $0.58 \pm 0.02$, respectively, indicating high efficiency in distinguishing genetic variation in the genotypes under study compared with the EST-SSRs with mean He and PIC of $0.48 \pm 0.02$ and $0.43 \pm 0.02$, respectively.

Genetic diversity across origins, growth habits and number of ear rows groups. To compare among groups' genetic variation based on gSSR and EST-SSR, the barley genotypes were grouped based on their (i) origins and breeding history, (ii) growth habits and (iii) the number of ear rows. Genetic diversity parameters for these groups are presented in Table 4 . The mean number of different alleles $(\mathrm{Na})$, effective number of alleles $(\mathrm{Ne})$, Shannon's index (I), unbiased expected heterozygosity ( $\mathrm{uHe}$ ) and number of private alleles (Npa) calculated based on the allelic variation of 77 EST-SSRs were slightly higher for Iranian landraces $(3.29,2.18$, $0.83,0.47$ and 5 , respectively) compared with exotic landraces (3.20, 2.10, 0.80, 0.46 and 4 , respectively), but the differences were not significant (Wilcoxon test, $\mathrm{p}$-value $=0.10$ ). However, the mean of all parameters was lower for "varieties and advanced breeding lines" $(2.71,1.86,0.66,0.39$ and 2 , respectively) compared with the landraces. Comparison of the parameters calculated based $72 \mathrm{gSSR}$ data showed that the Iranian landraces and exotic landraces were equivalent in mean values of $\mathrm{Na}, \mathrm{Ne}$, I and uHe, but the number of private alleles in Iranian landraces (32 alleles) was significantly higher compared with exotic landraces (11 alleles) (Wilcoxon test, 


\begin{tabular}{|c|c|c|c|c|c|c|c|c|c|c|c|c|c|c|c|}
\hline Marker & Ch & MAF & $\mathrm{Na}$ & $\mathrm{Ne}$ & I & $\mathrm{He}$ & PIC & Marker & Ch & MAF & $\mathrm{Na}$ & $\mathrm{Ne}$ & I & $\mathrm{He}$ & PIC \\
\hline GBM1143 & $1 \mathrm{H}$ & 0.46 & 4 & 3.87 & 1.51 & 0.65 & 0.59 & GBM1450 & $3 \mathrm{H}$ & 0.47 & 3 & 2.35 & 0.93 & 0.57 & 0.48 \\
\hline GBM1216 & $1 \mathrm{H}$ & 0.57 & 2 & 1.96 & 0.68 & 0.49 & 0.37 & SCSSR1559 & $3 \mathrm{H}$ & 0.51 & 5 & 2.95 & 1.30 & 0.66 & 0.62 \\
\hline GBM1336 & $1 \mathrm{H}$ & 0.56 & 3 & 2.07 & 0.79 & 0.52 & 0.41 & SCSSR25538 & $3 \mathrm{H}$ & 0.81 & 2 & 1.44 & 0.49 & 0.31 & 0.26 \\
\hline GBM1411 & $1 \mathrm{H}$ & 0.97 & 2 & 1.25 & 0.35 & 0.06 & 0.06 & SCSSR25691 & $3 \mathrm{H}$ & 0.52 & 4 & 2.72 & 1.15 & 0.63 & 0.58 \\
\hline GBM1451 & $1 \mathrm{H}$ & 0.68 & 6 & 2.05 & 1.10 & 0.51 & 0.49 & GBM1299 & $4 \mathrm{H}$ & 0.89 & 3 & 1.25 & 0.42 & 0.20 & 0.19 \\
\hline GBM1461 & $1 \mathrm{H}$ & 0.36 & 5 & 3.79 & 1.40 & 0.74 & 0.69 & GBM1221 & $4 \mathrm{H}$ & 0.36 & 7 & 3.90 & 1.54 & 0.74 & 0.70 \\
\hline GBM1480 & $1 \mathrm{H}$ & 0.76 & 2 & 1.58 & 0.55 & 0.37 & 0.30 & GBM1388 & $4 \mathrm{H}$ & 0.69 & 2 & \begin{tabular}{|l|}
1.74 \\
\end{tabular} & 0.62 & 0.43 & 0.34 \\
\hline SCSSR04163 & $1 \mathrm{H}$ & 0.65 & 5 & 2.12 & 1.02 & 0.53 & 0.48 & GBM1422 & $4 \mathrm{H}$ & 0.57 & 4 & 2.51 & 1.10 & 0.60 & 0.55 \\
\hline GBM1149 & $2 \mathrm{H}$ & 0.90 & 2 & 1.23 & 0.33 & 0.19 & 0.17 & GBM1482 & $4 \mathrm{H}$ & 0.44 & 6 & 3.81 & 1.45 & 0.72 & 0.68 \\
\hline GBM1208 & $2 \mathrm{H}$ & 0.39 & 3 & 2.96 & 1.09 & 0.66 & 0.59 & GBM1525 & $4 \mathrm{H}$ & 0.71 & 3 & 1.84 & 0.80 & 0.46 & 0.41 \\
\hline GBM1251 & $2 \mathrm{H}$ & 0.63 & 3 & 2.02 & 0.83 & 0.50 & 0.43 & SCSSR14079 & $4 \mathrm{H}$ & 0.39 & 5 & 3.77 & 1.45 & 0.73 & 0.69 \\
\hline GBM1309 & $2 \mathrm{H}$ & 0.55 & 3 & 2.38 & 0.96 & 0.58 & 0.50 & SCSSR18005 & $4 \mathrm{H}$ & 0.49 & 3 & 2.15 & 0.82 & 0.53 & 0.43 \\
\hline GBM1365 & $2 \mathrm{H}$ & 0.51 & 2 & 2.00 & 0.69 & 0.50 & \begin{tabular}{|l|}
0.37 \\
\end{tabular} & SCSSR20569 & $4 \mathrm{H}$ & 0.46 & 5 & 2.84 & 1.18 & 0.65 & 0.58 \\
\hline GBM1366 & $2 \mathrm{H}$ & 0.89 & 2 & 1.25 & 0.35 & 0.20 & 0.18 & GBM5939 & $5 \mathrm{H}$ & 0.54 & 3 & 2.19 & 0.86 & 0.54 & 0.45 \\
\hline GBM1408 & $2 \mathrm{H}$ & 0.94 & 2 & 1.12 & 0.22 & 0.10 & 0.10 & GBM1176 & $5 \mathrm{H}$ & 0.83 & 3 & 1.41 & 0.56 & 0.29 & 0.27 \\
\hline GBM1459 & $2 \mathrm{H}$ & 0.58 & 2 & 1.96 & 0.68 & 0.49 & 0.37 & GBM1293 & $5 \mathrm{H}$ & 0.67 & 3 & 1.98 & 0.86 & 0.49 & 0.44 \\
\hline GBM1468 & $2 \mathrm{H}$ & 0.72 & 3 & 1.80 & 0.79 & 0.45 & 0.40 & GBM1295 & $5 \mathrm{H}$ & 0.72 & 2 & 1.68 & 0.59 & 0.40 & 0.32 \\
\hline SCSSR3381 & $2 \mathrm{H}$ & 0.27 & 5 & 4.32 & 1.51 & 0.77 & 0.73 & GBM1398 & $5 \mathrm{H}$ & 0.80 & 2 & 1.48 & 0.51 & 0.33 & 0.27 \\
\hline SCSSR8447 & $2 \mathrm{H}$ & 0.69 & 3 & 1.88 & 0.82 & 0.47 & 0.42 & GBM1426 & $5 \mathrm{H}$ & 0.64 & 2 & 1.86 & 0.65 & 0.46 & 0.35 \\
\hline SCSSR12344 & $2 \mathrm{H}$ & 0.65 & 3 & 2.08 & 0.89 & 0.52 & 0.46 & GBM1436 & $5 \mathrm{H}$ & 0.79 & 3 & 1.53 & 0.65 & 0.35 & 0.32 \\
\hline GBM1110 & $3 \mathrm{H}$ & 0.55 & 3 & 2.36 & 0.95 & 0.58 & 0.50 & GBM1438 & $5 \mathrm{H}$ & 0.49 & 3 & 2.52 & 0.99 & 0.60 & 0.52 \\
\hline GBM1139 & $3 \mathrm{H}$ & 0.60 & 2 & 1.93 & 0.67 & 0.48 & 0.37 & GBM1463 & $5 \mathrm{H}$ & 0.80 & 3 & 1.50 & 0.61 & 0.33 & 0.30 \\
\hline GBM1159 & $3 \mathrm{H}$ & 0.62 & 3 & 2.20 & 0.93 & 0.54 & 0.49 & GBM1470 & $5 \mathrm{H}$ & 0.49 & 3 & 2.20 & 0.86 & 0.55 & 0.44 \\
\hline GBM1405 & $3 \mathrm{H}$ & 0.64 & 3 & 2.35 & 0.93 & 0.52 & 0.46 & GBM1506 & $5 \mathrm{H}$ & 0.38 & 5 & 3.40 & 1.35 & 0.71 & 0.65 \\
\hline GBM1413 & $3 \mathrm{H}$ & 0.41 & 6 & 3.87 & 1.51 & 0.74 & 0.70 & GBM5028 & $5 \mathrm{H}$ & 0.60 & 2 & 1.92 & 0.67 & 0.48 & 0.36 \\
\hline SCSSR2306 & $5 \mathrm{H}$ & 0.66 & 3 & 2.02 & 0.87 & 0.51 & 0.45 & GBM1126 & $7 \mathrm{H}$ & 0.51 & 3 & 2.11 & 0.80 & 0.53 & 0.42 \\
\hline SCSSR2503 & $5 \mathrm{H}$ & 0.69 & 2 & 1.76 & 0.66 & 0.43 & 0.34 & GBM1297 & $7 \mathrm{H}$ & \begin{tabular}{|l|}
0.94 \\
\end{tabular} & 2 & 1.13 & 0.24 & 0.12 & 0.11 \\
\hline SCSSR3907 & $5 \mathrm{H}$ & 0.30 & 7 & 5.18 & 1.75 & 0.81 & 0.78 & GBM1419 & $7 \mathrm{H}$ & 0.94 & 3 & 1.14 & 0.26 & 0.12 & 0.12 \\
\hline SCSSR10148 & $5 \mathrm{H}$ & 0.45 & 8 & 3.81 & 1.65 & 0.74 & 0.71 & GBM1428 & $7 \mathrm{H}$ & 0.56 & 2 & \begin{tabular}{|l|}
1.97 \\
\end{tabular} & 0.69 & 0.49 & 0.37 \\
\hline SCSSR15334 & $5 \mathrm{H}$ & 0.41 & 5 & 3.12 & 1.3 & 0.68 & 0.62 & GBM1432 & $7 \mathrm{H}$ & 0.87 & 2 & 1.29 & 0.38 & 0.22 & 0.20 \\
\hline SCSSR18076 & $5 \mathrm{H}$ & 0.83 & 2 & 1.39 & 0.46 & 0.28 & 0.24 & GBM1464 & $7 \mathrm{H}$ & 0.51 & 6 & 3.04 & 1.37 & 0.67 & 0.63 \\
\hline GBM175 & $6 \mathrm{H}$ & 0.65 & 3 & 2.02 & 0.85 & 0.50 & 0.44 & GBM1472 & $7 \mathrm{H}$ & 0.88 & 2 & 1.27 & 0.37 & 0.21 & 0.19 \\
\hline GBM1212 & $6 \mathrm{H}$ & 0.87 & 3 & 1.31 & 0.48 & 0.24 & 0.23 & GBM1516 & $7 \mathrm{H}$ & 0.65 & 4 & 2.05 & 0.92 & 0.51 & 0.46 \\
\hline GBM1267 & $6 \mathrm{H}$ & 0.84 & 2 & 1.38 & 0.44 & 0.27 & 0.24 & SCSSR15864 & $7 \mathrm{H}$ & 0.44 & 4 & 3.35 & 1.30 & 0.70 & 0.65 \\
\hline GBM1276 & $6 \mathrm{H}$ & 0.61 & 3 & 2.17 & 0.90 & 0.54 & 0.47 & SCSSR7970-1 & $7 \mathrm{H}$ & 0.59 & 5 & 2.26 & 1.04 & 0.56 & 0.49 \\
\hline GBM1400 & $6 \mathrm{H}$ & 0.88 & 3 & 1.28 & 0.45 & 0.22 & 0.21 & SCSSR7970-2 & $7 \mathrm{H}$ & 0.54 & 4 & 2.60 & 1.10 & 0.62 & 0.56 \\
\hline GBM1404 & $6 \mathrm{H}$ & 0.96 & 2 & 1.09 & 0.18 & 0.08 & 0.08 & GBM1552 & - & 0.79 & 2 & 1.49 & 0.51 & 0.33 & 0.27 \\
\hline SCSSR5599 & $6 \mathrm{H}$ & 0.41 & 4 & 3.35 & 1.29 & 0.70 & 0.65 & Mean & & 0.56 & 3.4 & 2.28 & 0.87 & 0.48 & 0.43 \\
\hline SCSSR9398 & $6 \mathrm{H}$ & 0.21 & 9 & 7.00 & 2.05 & 0.86 & 0.84 & SE & - & 0.02 & 0.18 & 0.12 & 0.05 & 0.02 & 0.02 \\
\hline GBM1116 & $7 \mathrm{H}$ & 0.86 & 2 & 1.33 & 0.41 & 0.25 & 0.22 & & & & & & & & \\
\hline
\end{tabular}

Table 2. Description of the used EST-SSR loci including chromosome location (Ch), major allele frequency (MAF), number of alleles (Na), effective number of alleles (Ne), Shannon's information index (I), gene diversity (He) and polymorphic information (PIC).

p-value $\leq 0.001)$. For this marker set, "varieties and advanced breeding lines showed the lower mean value of $\mathrm{Na}$ (4.12), $\mathrm{Ne}$ (2.73), I (1.05), and (0.56) except Npa which was 12 compared with 11 for exotic landraces.

The mean values of $\mathrm{Na}, \mathrm{Ne}$, I and uHe estimated based on EST-SSR data were slightly higher in winter growth habit $(3.31,2.25,0.85$ and 0.49 , respectively) than spring growth habit $(3.19,1.92,0.72$ and 0.41 , respectively), but significantly higher than facultative genotypes $(2.42,1.77,0.59$ and 0.36 , respectively) (Wilcoxon, p-values $\leq 0.01$ ). A total of 14, 3 and zero EST-SSR private alleles were detected in winter, spring and facultative growth habits, respectively. Higher diversity was observed among the genotypes with various growth habits using gSSR markers compared with EST-SRRs. The mean values of $\mathrm{Na}, \mathrm{Ne}, \mathrm{I}$, uHe and $\mathrm{Npa}$ in winter growth habit genotypes were $5.64,3.85,1.32,0.65$, and 44 , respectively, compared with $5.25,3.10,1.12,0.55$ and 17 , respectively, in spring growth habit and 3.39, 2.36, 0.86, 0.48 and zero, respectively, in facultative genotypes.

Considering ear row number, mean $\mathrm{Na}, \mathrm{Ne}, \mathrm{I}$, uHe and Npa of EST-SSRs in two-row genotypes were 3.21, $1.94,0.72,0.411$ and 8 , compared with $3.29,2.22,0.84,048$ and 14 , respectively in six-row genotypes. The mean of these parameters for gSSRs were 5.37, 3.06, 1.10, 0.54 and 13, in two-row barley and 5.58, 3.77, 1.31, 0.65 and 41, respectively in six-row barley. The analysis revealed slightly higher genetic diversity in six-row genotypes 


\begin{tabular}{|c|c|c|c|c|c|c|c|c|c|c|c|c|c|c|c|}
\hline Marker & Ch & MAF & $\mathrm{Na}$ & $\mathrm{Ne}$ & I & $\mathrm{He}$ & PIC & Marker & Ch & MAF & $\mathrm{Na}$ & $\mathrm{Ne}$ & I & $\mathrm{He}$ & PIC \\
\hline Bmac32 & $1 \mathrm{H}$ & 0.15 & 15 & 10.06 & 2.43 & 0.90 & 0.89 & HVM36 & $2 \mathrm{H}$ & 0.62 & 3 & 2.00 & 0.80 & 0.50 & 0.41 \\
\hline Bmac63 & $1 \mathrm{H}$ & 0.16 & 9 & 7.85 & 2.11 & \begin{tabular}{|l|}
0.87 \\
\end{tabular} & 0.86 & $\operatorname{mac} 209$ & $3 \mathrm{H}$ & 0.36 & 7 & 3.80 & 1.53 & 0.74 & 0.70 \\
\hline Bmac213 & $1 \mathrm{H}$ & 0.20 & 10 & 7.96 & 2.18 & \begin{tabular}{|l|}
0.87 \\
\end{tabular} & 0.86 & Bmag013 & $3 \mathrm{H}$ & 0.35 & 6 & 3.57 & 1.41 & 0.72 & 0.67 \\
\hline Bmag149 & $1 \mathrm{H}$ & 0.53 & 5 & 2.56 & 1.08 & \begin{tabular}{|l|}
0.61 \\
\end{tabular} & 0.54 & EBmac225 & $3 \mathrm{H}$ & 0.18 & 11 & 8.24 & 2.23 & 0.88 & \begin{tabular}{|l|} 
\\
\end{tabular} \\
\hline Bmag211 & $1 \mathrm{H}$ & 0.38 & 5 & 3.43 & 1.34 & 0.71 & 0.65 & EBmac541 & $3 \mathrm{H}$ & 0.51 & 6 & 2.97 & 1.31 & 0.66 & 0.62 \\
\hline Bmag45 & $1 \mathrm{H}$ & 0.49 & 5 & 2.51 & 1.04 & 0.60 & 0.52 & EBmac871 & $3 \mathrm{H}$ & 0.23 & 8 & 6.23 & 1.94 & 0.84 & 0.82 \\
\hline Bmag82 & $1 \mathrm{H}$ & 0.47 & 7 & 3.45 & 1.51 & 0.71 & 0.68 & GBMS183 & $3 \mathrm{H}$ & 0.48 & 5 & 3.22 & 1.37 & 0.69 & 0.65 \\
\hline Bmag504 & $1 \mathrm{H}$ & 0.57 & 3 & 2.01 & 0.75 & 0.50 & 0.39 & GMS116 & $3 \mathrm{H}$ & 0.18 & 10 & 8.05 & 2.17 & 0.88 & 0.86 \\
\hline EBmac560 & $1 \mathrm{H}$ & 0.74 & 2 & 1.64 & 0.58 & 0.39 & 0.31 & HV13 & $3 \mathrm{H}$ & 0.67 & 3 & 1.93 & 0.82 & 0.48 & 0.42 \\
\hline EBmac659 & $1 \mathrm{H}$ & 0.94 & 2 & 1.12 & 0.21 & 0.10 & 0.10 & HV13GEIII & $3 \mathrm{H}$ & 0.65 & 3 & 2.02 & 0.85 & 0.50 & 0.44 \\
\hline HVM20 & $1 \mathrm{H}$ & 0.79 & 2 & 1.49 & 0.51 & 0.33 & 0.27 & HVES1A & $3 \mathrm{H}$ & 0.73 & 2 & 1.65 & 0.59 & 0.40 & 0.32 \\
\hline HVM43 & $1 \mathrm{H}$ & 0.94 & 4 & 1.12 & 0.27 & 0.11 & 0.11 & Bmac310 & $4 \mathrm{H}$ & 0.39 & 8 & 4.39 & 1.71 & 0.77 & \begin{tabular}{|l}
0.75 \\
\end{tabular} \\
\hline Bmac132 & $2 \mathrm{H}$ & 0.80 & 2 & 1.47 & 0.50 & 0.32 & 0.27 & Bmag375 & $4 \mathrm{H}$ & 0.50 & 3 & 2.68 & 1.04 & 0.63 & 0.56 \\
\hline Bmac134 & $2 \mathrm{H}$ & 0.59 & 8 & 2.62 & 1.38 & 0.62 & 0.59 & Bmag419 & $4 \mathrm{H}$ & 0.29 & 8 & 5.47 & 1.86 & 0.82 & 0.79 \\
\hline Bmag114 & $2 \mathrm{H}$ & 0.82 & 2 & 1.43 & 0.48 & 0.30 & 0.26 & \begin{tabular}{|l|} 
Bmag740 \\
\end{tabular} & $4 \mathrm{H}$ & 0.34 & 14 & 5.03 & 2.01 & 0.80 & $\begin{array}{l}0.78 \\
\end{array}$ \\
\hline Bmag140 & $2 \mathrm{H}$ & 0.52 & 3 & 2.52 & 1.08 & 0.60 & 0.53 & \begin{tabular}{|l|} 
Bmag138 \\
\end{tabular} & $4 \mathrm{H}$ & 0.57 & 8 & 2.82 & 1.47 & 0.65 & 0.62 \\
\hline Bmag378 & $2 \mathrm{H}$ & 0.52 & 3 & 2.59 & 1.02 & 0.61 & 0.54 & EBmac635 & $4 \mathrm{H}$ & 0.29 & 10 & 6.37 & 2.06 & 0.84 & 0.83 \\
\hline Bmag518 & $2 \mathrm{H}$ & 0.48 & 5 & 3.04 & 1.30 & 0.67 & 0.62 & EBmac788 & $4 \mathrm{H}$ & 0.14 & 12 & 10.65 & 2.42 & 0.91 & 0.90 \\
\hline Bmag720 & $2 \mathrm{H}$ & 0.18 & 11 & 7.37 & 2.13 & 0.86 & 0.85 & EBmac906 & $4 \mathrm{H}$ & 0.29 & 8 & 4.75 & 1.70 & 0.79 & 0.76 \\
\hline Bmag813 & $2 \mathrm{H}$ & 0.31 & 9 & 5.38 & 1.87 & 0.81 & 0.79 & EBmac679 & $4 \mathrm{H}$ & 0.23 & 10 & 6.88 & 2.06 & 0.85 & 0.84 \\
\hline EBmac525 & $2 \mathrm{H}$ & 0.71 & 3 & 1.76 & 0.71 & 0.43 & 0.36 & GMS89 & $4 \mathrm{H}$ & 0.35 & 5 & 3.55 & 1.37 & 0.72 & 0.67 \\
\hline EBmac558 & $2 \mathrm{H}$ & 0.92 & 2 & 1.16 & 0.27 & 0.14 & 0.13 & HVBAMY & $4 \mathrm{H}$ & 0.57 & 3 & 2.36 & 0.97 & 0.58 & 0.51 \\
\hline EBmac854 & $2 \mathrm{H}$ & 0.74 & 4 & 1.71 & 0.80 & 0.41 & 0.38 & HVM68 & $4 \mathrm{H}$ & 0.47 & 5 & 2.79 & 1.17 & 0.64 & 0.58 \\
\hline EBmatc39 & $2 \mathrm{H}$ & 0.71 & 2 & 1.70 & 0.60 & 0.41 & 0.33 & HVM40 & $4 \mathrm{H}$ & 0.31 & 5 & 3.99 & 1.46 & 0.75 & 0.71 \\
\hline GBMS0160 & $2 \mathrm{H}$ & 0.39 & 9 & 4.67 & 1.85 & \begin{tabular}{|l|}
0.79 \\
\end{tabular} & \begin{tabular}{|l|}
0.77 \\
\end{tabular} & HVM51 & $4 \mathrm{H}$ & 0.61 & 2 & 1.91 & \begin{tabular}{|l|}
0.67 \\
\end{tabular} & 0.48 & 0.36 \\
\hline Bmac96 & $5 \mathrm{H}$ & 0.54 & 4 & 2.70 & 1.17 & 0.63 & 0.58 & Bmac167 & $7 \mathrm{H}$ & 0.55 & 3 & 2.28 & 0.92 & 0.56 & 0.48 \\
\hline Bmac113 & $5 \mathrm{H}$ & 0.28 & 6 & 4.80 & 1.66 & \begin{tabular}{|l|}
0.79 \\
\end{tabular} & 0.76 & Bmag507 & $7 \mathrm{H}$ & 0.15 & 14 & 9.74 & 2.41 & 0.90 & \begin{tabular}{|l}
0.89 \\
\end{tabular} \\
\hline Bmac163 & $5 \mathrm{H}$ & 0.84 & 4 & 1.38 & 0.57 & 0.28 & 0.26 & Bmag516 & $7 \mathrm{H}$ & 0.29 & 8 & 5.85 & 1.90 & 0.83 & 0.81 \\
\hline Bmag751 & $5 \mathrm{H}$ & 0.38 & 5 & 3.65 & 1.42 & 0.73 & 0.68 & EBmag794 & $7 \mathrm{H}$ & 0.80 & 3 & 1.51 & 0.63 & 0.34 & 0.31 \\
\hline Bmag812 & $5 \mathrm{H}$ & 0.69 & 5 & 1.96 & \begin{tabular}{|l|}
0.99 \\
\end{tabular} & \begin{tabular}{|l|}
0.49 \\
\end{tabular} & 0.46 & EBmatc16 & $7 \mathrm{H}$ & 0.21 & 11 & 6.53 & 2.01 & 0.85 & 0.83 \\
\hline Bmac40 & $6 \mathrm{H}$ & 0.24 & 12 & 7.93 & 2.67 & 0.87 & 0.86 & GBMS141 & $7 \mathrm{H}$ & 0.23 & 10 & 6.84 & 2.08 & 0.85 & 0.84 \\
\hline Bmag9 & $6 \mathrm{H}$ & 0.30 & 5 & 3.90 & 1.44 & \begin{tabular}{|l|}
0.74 \\
\end{tabular} & 0.70 & GMS46 & $7 \mathrm{H}$ & 0.70 & 3 & 1.87 & 0.82 & 0.46 & 0.42 \\
\hline Bmag807 & $6 \mathrm{H}$ & 0.63 & 5 & 2.22 & 1.07 & 0.55 & 0.50 & HVM49 & $7 \mathrm{H}$ & 0.38 & 7 & 3.33 & 1.44 & 0.70 & 0.65 \\
\hline EBmac624 & $6 \mathrm{H}$ & 0.48 & 3 & 2.69 & 1.04 & 0.63 & 0.55 & HVLMNO1A & - & 0.87 & 4 & 1.31 & 0.51 & 0.24 & 0.22 \\
\hline GBMS180 & $6 \mathrm{H}$ & 0.35 & 6 & 4.47 & 1.63 & \begin{tabular}{|l|}
0.78 \\
\end{tabular} & 0.74 & MGB384 & - & 0.62 & 2 & 1.90 & 0.67 & 0.47 & 0.36 \\
\hline HVM31 & $6 \mathrm{H}$ & 0.54 & 2 & 1.99 & 0.69 & 0.50 & 0.37 & Mean & & 0.48 & 5.96 & 3.83 & 1.32 & 0.63 & $\begin{array}{l}0.58 \\
\end{array}$ \\
\hline HVM74 & $6 \mathrm{H}$ & 0.22 & 10 & 7.07 & 2.10 & 0.86 & 0.84 & SE & - & 0.02 & 0.34 & 0.23 & 0.06 & 0.02 & 0.02 \\
\hline
\end{tabular}

Table 3. Description of the used genomic SSR loci including chromosome location (Ch), major allele frequency (MAF), number of alleles (Na), effective number of alleles (Ne), Shannon's information index (I), gene diversity $(\mathrm{He})$ and polymorphic information (PIC).

\begin{tabular}{|c|c|c|c|c|c|c|c|c|c|c|c|}
\hline \multirow[b]{2}{*}{ Origin/type } & \multirow[b]{2}{*}{ NS } & \multicolumn{2}{|l|}{$\mathrm{Na}$} & \multicolumn{2}{|l|}{$\mathrm{Ne}$} & \multicolumn{2}{|l|}{ I } & \multicolumn{2}{|l|}{ uHe } & \multicolumn{2}{|l|}{ Npa } \\
\hline & & \begin{tabular}{|l|} 
EST-SSR \\
\end{tabular} & gSSR & EST-SSR & gSSR & EST-SSR & gSSR & \begin{tabular}{|l|} 
EST-SSR \\
\end{tabular} & gSSR & \begin{tabular}{|l} 
EST-SSR \\
\end{tabular} & gSSR \\
\hline Iranian landraces & 69 & $3.29(0.17)$ & $5.53(0.38)$ & $2.18(0.11)$ & $4.07(0.23)$ & $0.83(0.04)$ & $1.25(0.07)$ & $0.47(0.02)$ & $0.61(0.03)$ & 5 & 32 \\
\hline Exotic landraces & 50 & $3.20(0.15)$ & $5.17(0.33)$ & $2.10(0.10)$ & $3.88(0.21)$ & $0.80(0.04)$ & $1.20(0.06)$ & $0.46(0.02)$ & $0.60(0.02)$ & 4 & 11 \\
\hline $\begin{array}{l}\text { Cultivars and advanced } \\
\text { lines }\end{array}$ & 25 & $2.71(0.14)$ & $4.12(0.27)$ & $1.86(0.08)$ & $2.73(0.16)$ & $0.66(0.05)$ & $1.05(0.05)$ & $0.39(0.03)$ & $0.56(0.02)$ & 2 & 12 \\
\hline Spring & 61 & $3.19(0.16)$ & $5.25(0.33)$ & $1.92(0.09)$ & $3.10(0.24)$ & $0.72(0.04)$ & $1.12(0.07)$ & $0.41(0.02)$ & $0.55(0.03)$ & 3 & 17 \\
\hline Winter & 69 & $3.31(0.17)$ & $5.64(0.38)$ & $2.25(0.12)$ & $3.85(0.26)$ & $0.85(0.05)$ & $1.32(0.07)$ & $0.49(0.02)$ & $0.65(0.02)$ & 14 & 44 \\
\hline Facultative & 14 & $2.42(0.12)$ & $3.39(0.17)$ & $1.77(0.09)$ & $2.36(0.15)$ & $0.59(0.05)$ & $0.86(0.06)$ & $0.36(0.03)$ & $0.48(0.03)$ & - & - \\
\hline Two-row & 79 & $3.21(0.16)$ & $5.37(0.35)$ & $1.94(0.10)$ & $3.06(0.23)$ & $0.72(0.04)$ & $1.10(0.07)$ & $0.41(0.02)$ & $0.54(0.03)$ & 8 & 13 \\
\hline Six-row & 65 & $3.29(0.17)$ & $5.58(0.37)$ & $2.22(0.11)$ & $3.77(0.24)$ & $0.84(0.04)$ & $1.31(0.07)$ & $0.48(0.02)$ & $0.65(0.02)$ & 14 & 41 \\
\hline
\end{tabular}

Table 4. Allelic pattern of EST-SSR and gSSR markers across barley genotypes grouped based on origin, growth habit and number of ear rows. NS number of sample, $\mathrm{Na}$ number of different alleles, $\mathrm{Ne}$ effective number of alleles, I Shannon's information index, $u H e$ Unbiased expected heterozygosity, Npa private alleles. 

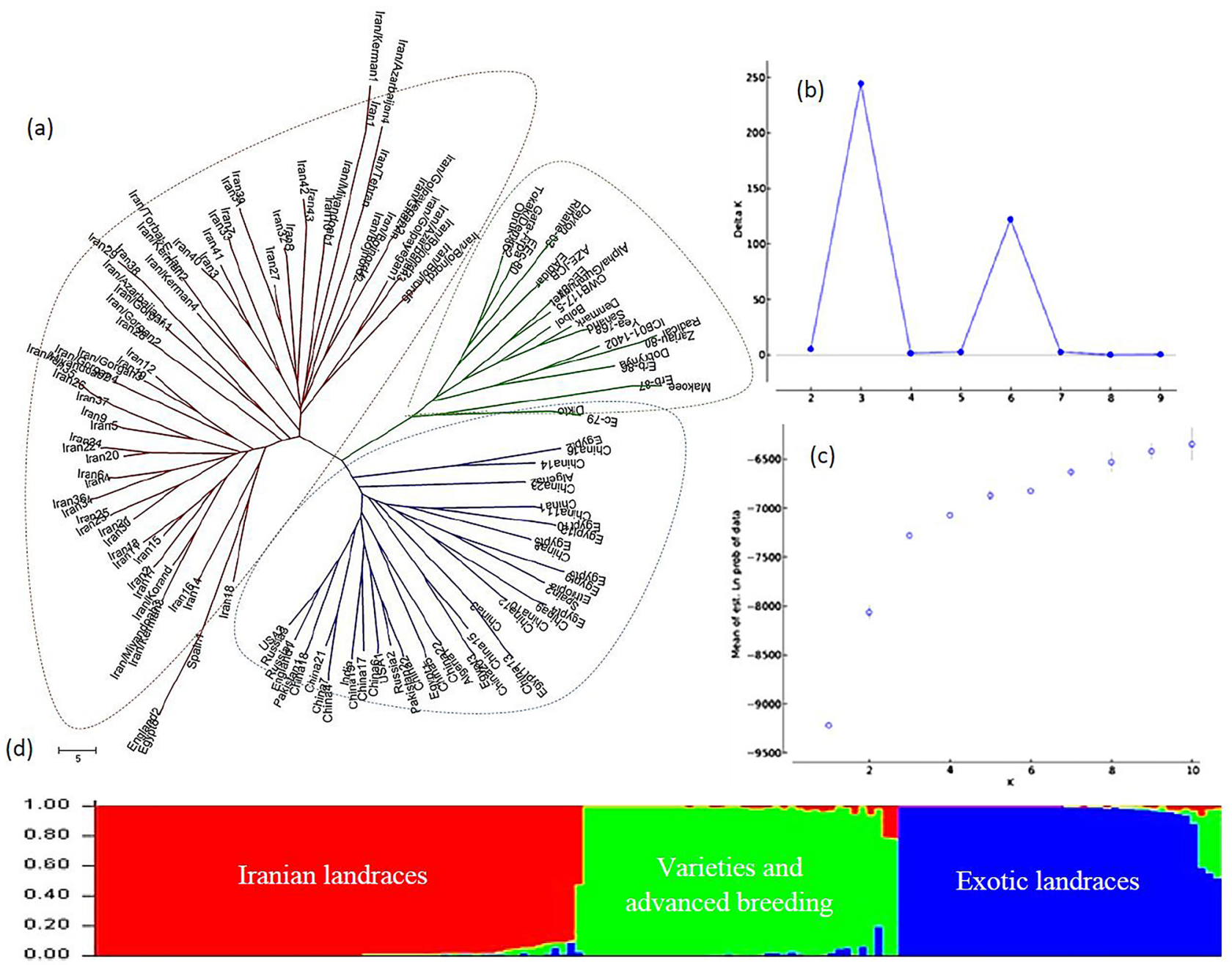

Figure 1. The genetic relationships and population structure of the 144 barley genotypes using EST-SSR data inferred by distance and model based cluster analyses. (a) Neighbor-Joining cluster analysis, (b) Delta K vs. K plotted for determining optimal numbers of subpopulations (K), (c) Mean Log probability values (LnP(D)) plotted as function of K (number of clusters) and (d) Estimated population structure on $\mathrm{K}=3$. Neighbor-Joining and model- based cluster analyses cold assign "Iranian landraces", "exotic landraces" and "varieties and advanced breeding lines" into separate groups.

compared with two-row genotypes, but the difference was only significant for Npa. However, allelic diversity calculated based on gSSR data was higher in both groups compared with EST-SSRs.

Inferring the population structure. In the model-based clustering using SSR, EST-SSR, and combined data sets, the log-likelihood value $[\mathrm{LnP}(\mathrm{D})]$ increased continuously as $\mathrm{K}$ changed from 1 to 10 , but inflection was evident when $\mathrm{K}$ increased from 2 to 3 (Figs. 1c, 2c, 3c). Thus, the most likely numerical value of $\mathrm{K}$ was 3 . The further validation of the optimal number of clusters $(\mathrm{K})$ was assessed using the second-order statistics of $\Delta \mathrm{K}$. The $\Delta \mathrm{K}$ value showed a peak at $\mathrm{K}=3$ (Figs. $1 \mathrm{~b}, 2 \mathrm{~b}, 3 \mathrm{~b}$ ), which supported the classification of the studied populations into three major sub-populations corresponding to Iranian landraces, exotic landraces and "varieties and advance breeding lines" (Figs. 1d, 2d, 3d). Considering a probability of membership threshold of 70\%, Iranian landraces, exotic landraces, and "varieties and advanced breeding lines" except few exceptions were assigned into three distinct sub-populations.

The distance-based cluster analysis using Neighbor-Joining algorithms and based on gSSR, EST-SSR, and combined data sets assigned the 144 barley genotypes into three clusters which were fully in agreement with the results of model-based clustering implemented in STRUCTURE (Figs. 1a, 2a, 3a). In the resulted phylogenetic trees, the Iranian landraces were grouped along with two landraces from Egypt and one from Spain. All the varieties and advanced breeding lines constructed a separate group and the exotic landraces were assigned into a distinct cluster.

The PCoA based on origin and breeding history of the barley genotypes using EST-SSR data could separate Iranian landraces, exotic landraces, and "cultivars and advanced breeding lines" into distinct groups. The 1st and 2 nd coordinates explained 18.47 and $15.73 \%$ molecular variation. The first coordinate discriminates Iranian 


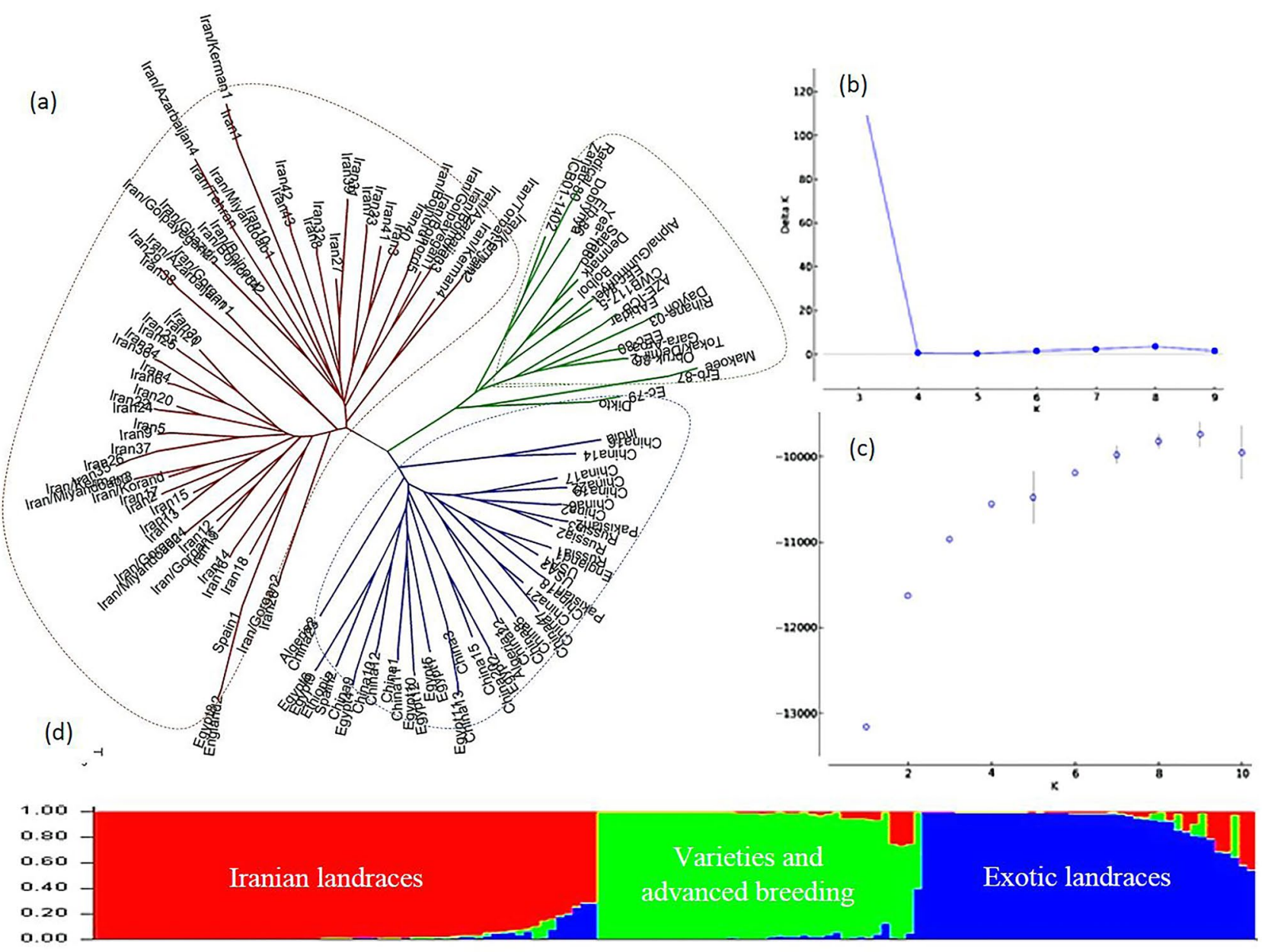

Figure 2. The genetic relationships and population structure of the 144 barley genotypes using SSR data inferred by distance and model based cluster analyses. (a) Neighbor-Joining cluster analysis, (b) Delta K vs. K plotted for determining optimal numbers of subpopulations (K), (c) Mean Log probability values (LnP(D)) plotted as function of $\mathrm{K}$ (number of clusters) and (d) Estimated population structure on $\mathrm{K}=3$. Neighbor-Joining and model- based cluster analyses cold assign "Iranian landraces", "exotic landraces" and "varieties and advanced breeding lines" into separate groups.

landraces from the other genotypes (Fig. 4a). In PCoA using gSSR data, 16.42 and $13.06 \%$ of molecular variation conserved by the 1st and 2nd coordinates, respectively. Plotting of the genotypes based on two first coordinates revealed some admixture between Iranian and exotic landraces (Fig. 4b). When PCoA was performed using EST-SSR + gSSR data, the 1st and 2nd coordinates explained 16.58 and $15.79 \%$ of the variation, respectively and biplot of the genotypes using 1 st and 2 nd coordinates could discriminate all three groups (Fig. 4c). The principal coordinate analysis was also conducted to discriminate genotype based on their growth habits (spring, winter, and facultative). Using EST-SSR, the 1st coordinate explaining $37.97 \%$ of genetic variation distinguished winter habit versus the spring and facultative types, while based the 2 nd coordinate accounting for $25.83 \%$ of the variation high admixture was observed among all growth habits (Fig. 5a). Analysis using gSSR and combination of EST-SSR, and gSSR data revealed better discrimination winter, spring and facultative genotypes. In both analyses, the 1st coordinate could separate wither types from spring and facultative genotypes and spring and facultative types were clustered into two distinct groups (Fig. 5b,c). Analysis of population structure between two- and six-row genotypes using PCoA based on EST-SSR, gSSR and EST-SSR + gSSR data showed discrimination of two groups in all analysis. The 1st coordinate accounting for 37.98, 39.35 and $40.89 \%$ of molecular variation of EST-SSR, gSSR and EST-SSR + gSSR data could distinguish two- and six-row barley (Fig. 6a-c).

The allelic pattern of EST-SSR and gSSR markers across barley genotype grouped based on origin and breeding history, growth habit, and number of ear rows are presented in Table 5 . The number of different alleles per locus (Na) in Iranian landraces, exotic landraces and "cultivars and advanced breeding lines" were 3.29, 3.20 and 2.71 for EST-SSRs and 5.53, 5.17 and 4.12 for gSSRs, respectively. The effective number of alleles (Ne) was also higher for gSSR markers $(4.07,3.88$ and 2.73) compared with EST-SSR marker $(2.18,2.10$, and 1.86) across Iranian landraces, exotic landraces and "cultivars and advanced breeding liners". Shannon's index (I) and unbiased expected heterozygosity ( $\mathrm{uHe}$ ) ranged from 0.66 to 0.88 and 0.39 to 0.47 , respectively for EST-SSR and 1.05 to 1.25 and 0.56 to 0.61 for gSSR markers. The number of private alleles was higher in Iranian landraces for both 

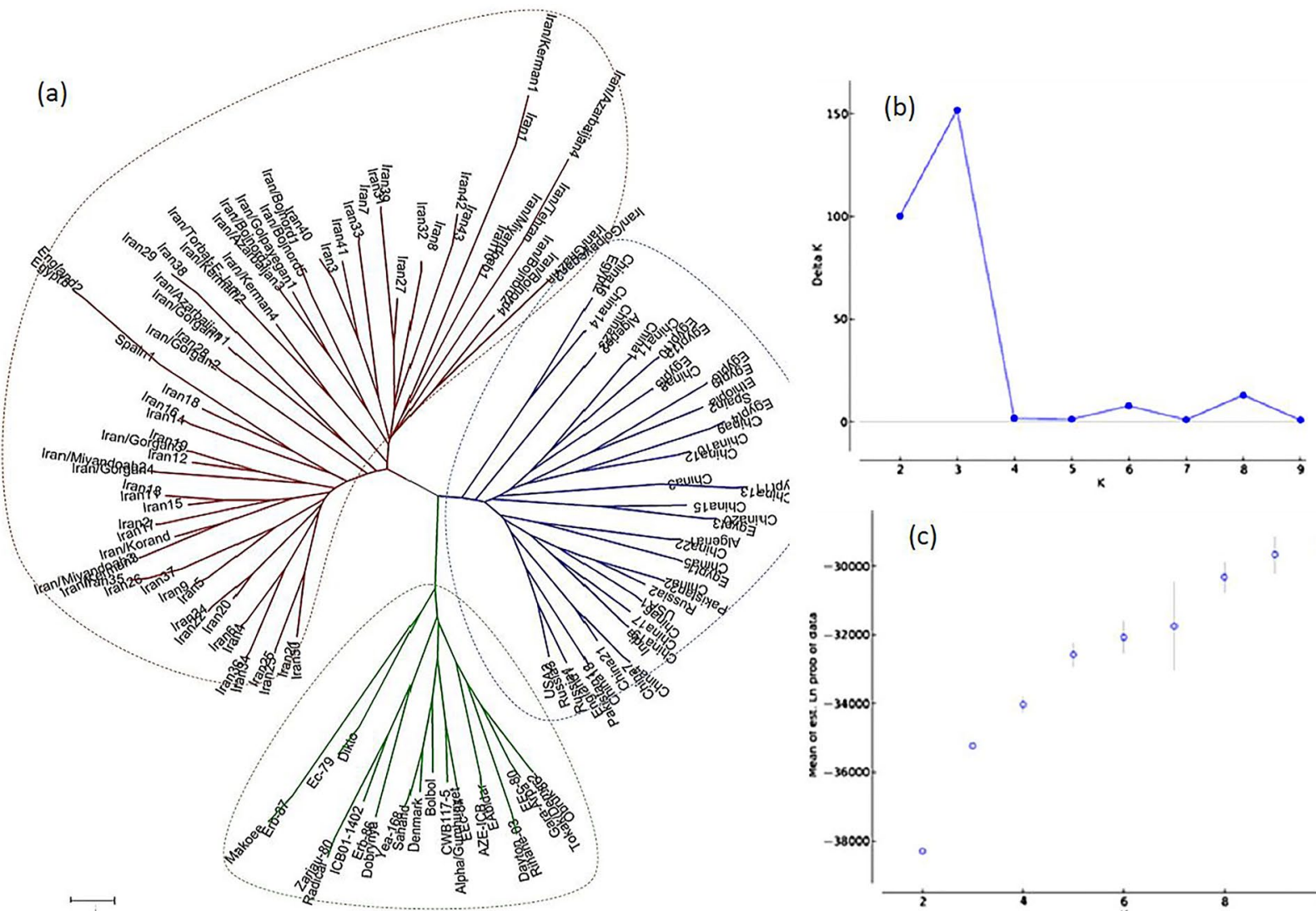

(d)

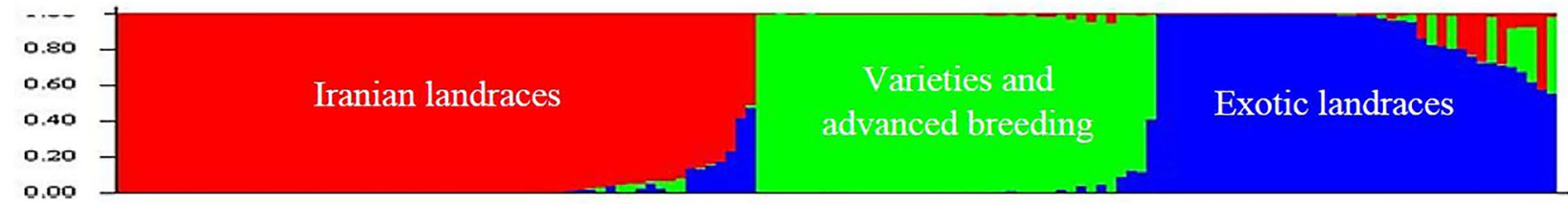

Figure 3. The genetic relationships and population structure of the 144 barley genotypes using EST-SSR and SSR data inferred by distance and model based cluster analyses. (a) Neighbor-Joining cluster analysis, (b) Delta K vs. K plotted for determining optimal numbers of subpopulations (K), (c) Mean Log probability values $(\mathrm{LnP}(\mathrm{D}))$ plotted as function of $\mathrm{K}$ (number of clusters) and (d) Estimated population structure on $\mathrm{K}=3$. Neighbor-Joining and model- based cluster analyses cold assign "Iranian landraces", "exotic landraces" and "varieties and advanced breeding lines" into separate groups.

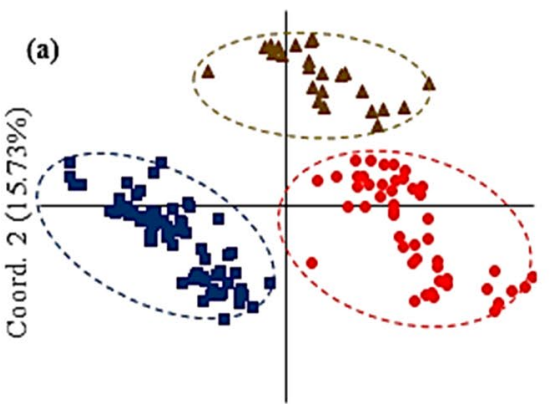

Coord. $1(18.47 \%)$
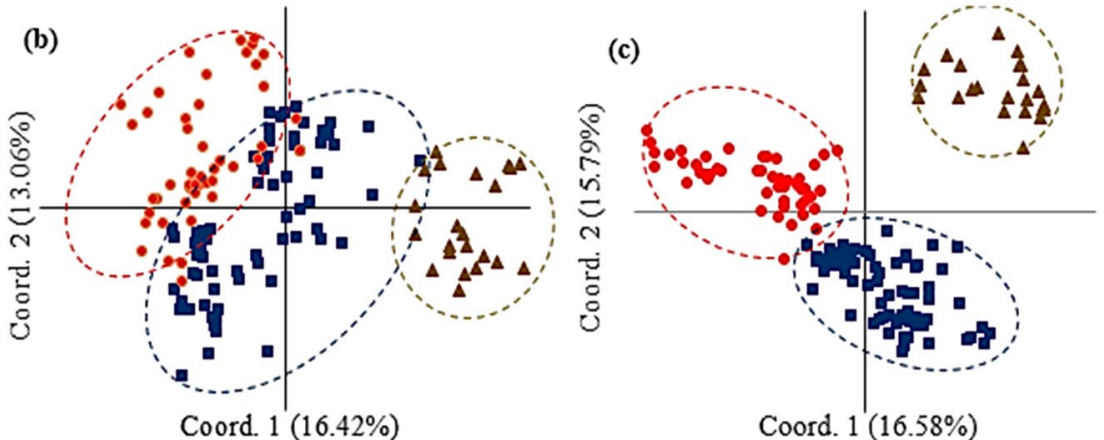

Coord. $1(16.58 \%)$

Figure 4. Principal coordinate analysis (PCoA) of 144 barley genotypes based on origins and breeding history [(blue diamonds) Iranian landraces, (red squares) exotic landraces and (brown triangles) cultivars and advanced breeding lines]. (a) EST-SSR, (b) gSSR and (c) EST-SSR + gSSR data. 


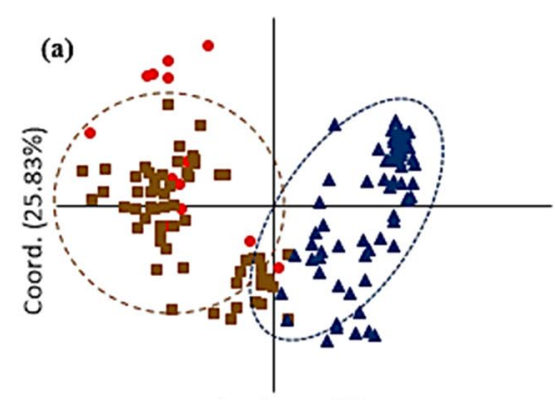

Coord. 1 (33.97\%)

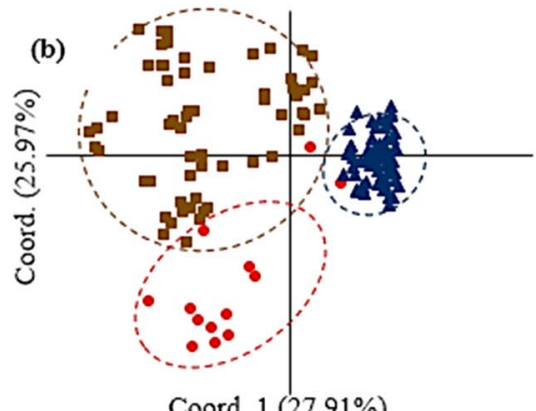

Coord. $1(27.91 \%)$

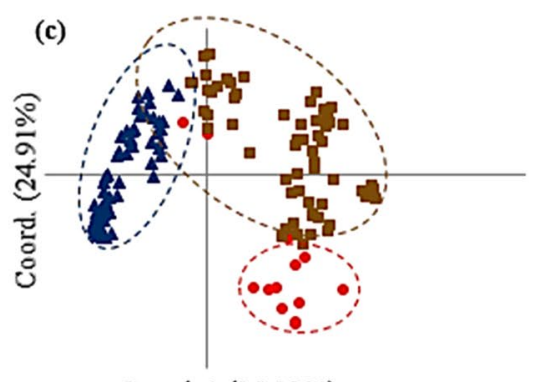

Coord. $1(25.92 \%)$

Figure 5. Principal coordinate analysis $(\mathrm{PCoA})$ of 144 barley genotypes based on growth habits [(red diamonds) facultative, (brown squares) spring and (blue triangles) winter]. (a) EST-SSR, (b) SSR and (c) ESTSSR + SSR data.

(a)

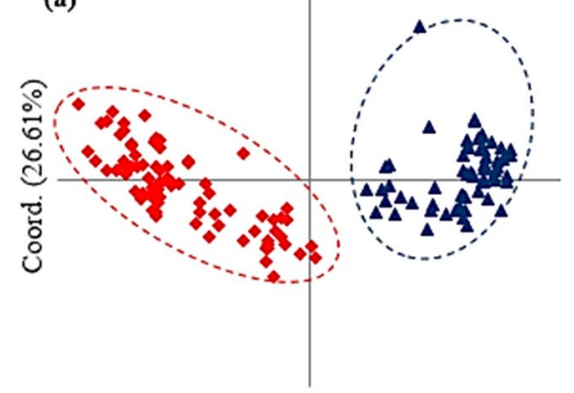

Coord. $1(37.98 \%)$

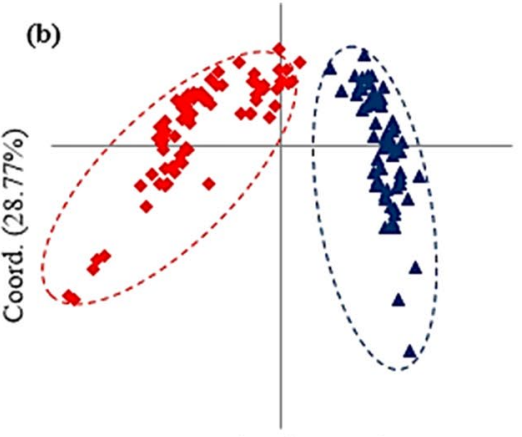

Coord. $1(39.35 \%)$

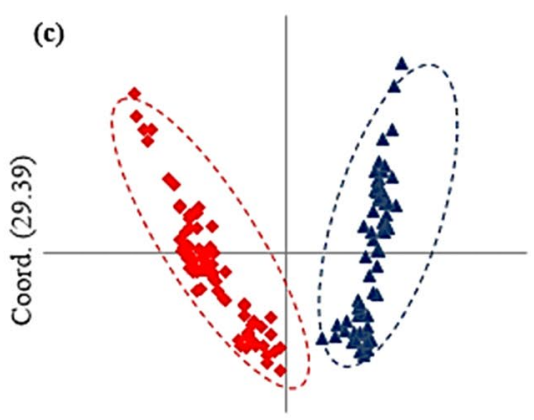

Coord. $1(40.89 \%)$

Figure 6. Principal coordinate analysis (PCoA) of 144 barley genotypes based on number of ear rows [(red diamonds) two- and (blue triangles) six-rowed]. (a) EST-SSR, (b) SSR and (c) EST-SSR + SSR data.

\begin{tabular}{|l|l|l|l|l|l|l|l|l|c|}
\hline \multirow{2}{*}{ Origin/country } & \multicolumn{7}{|l|}{ Two-rowed } & \multicolumn{3}{l|}{ Six-rowed } & \multirow{2}{*}{ Sum } \\
\hline & W & S & F & W & S & F & Sum \\
\hline Iranian landraces & 8 & 21 & 10 & 29 & 1 & 1 & 69 \\
\hline Exotic landraces & 2 & 8 & 2 & 9 & 2 & & 23 \\
\hline China & & 1 & & 8 & 2 & 1 & 12 \\
\hline Egypt & 1 & 1 & & & & & 2 \\
\hline Algeria & & 1 & & & & & 1 \\
\hline Denmark & & 1 & & 1 & & & 2 \\
\hline England & & 1 & & & & & 1 \\
\hline Ethiopia & & & & 1 & & & 1 \\
\hline India & & 2 & & & & & 2 \\
\hline Pakistan & & 3 & & & & & 3 \\
\hline Russia & & 1 & & 1 & & & 2 \\
\hline Spain & & 2 & & & & & 2 \\
\hline USA & 2 & 13 & & 7 & 2 & & 24 \\
\hline Cultivars and advanced breeding lines & 13 & 55 & 12 & 56 & 7 & 2 & 144 \\
\hline Sum & & & & & & \\
\hline
\end{tabular}

Table 5. Distribution of 144 barley landraces, cultivars and advanced breeding lines used in this study according to their origin, number of ear rows and growth habit. $W$ winter type, $S$ spring type, $F$ facultative type. 
markers (5 and 32 for EST-SSR and gSSR, respectively) compared with exotic landraces (4 and 11 for EST-SSR and SSR, respectively) and "cultivars and advanced breeding lines (2 and 12 for EST-SSR and SSR, respectively).

EST-SSR and gSSR diversity within spring barley as revealed by $\mathrm{Na}, \mathrm{Ne}$, I and uHe were not significantly differed from those of winter type but were higher compared with facultative genotypes. The higher number of private alleles were detected in winter genotypes (14 and 44 for EST-SSR and gSSR, respectively) compared with spring genotypes ( 3 and 17 for EST-SSR and gSSR, respectively) and facultative (no private allele). Genetic diversity based on ear row type revealed no major differences in the number of different alleles per locus and the effective number of alleles found in the two-row genotypes (EST-SSR: 3.21; gSSR: 5.37), (EST-SSR: 1.94; gSSR: 3.06) compared with the six-row genotypes (EST-SSR: 3.29, gSSR: 5.58), (EST-SSR: 2.22, gSSR: 3.77). But the genetic diversity as revealed by Shannon's index and unbiased expected heterozygosity was higher in the six-row genotypes (EST-SSR: 0.84; gSSR: 1.31) and (EST-SSR: 0.48; gSSR: 0.65) compared with the two-row genotypes (EST-SSR: 0.72; gSSR: 1.10) and (EST-SSR: 0.41; gSSR: 0.54). The six-row genotypes had also a higher number of private alleles (EST-SSR: 14; gSSR: 41) compared with the two-row Genotypes (EST-SSR: 8; gSSR: 13).

\section{Discussion}

Knowledge of population structure and genetic relationships among the genotypes is a prerequisite for plant breeding programs as well as for emerging genome-wide association studies (GWAS) as an alternate approach for QTL detection in comparison to linkage map-based QTL analysis ${ }^{23}$. Besides, to achieve future production under changing environments, greater genetic diversity than that is present in current elite germplasms will be needed $^{24}$. Fortunately, an extensive reservoir of biodiversity has been stored in genebanks as seeds of historical breeding materials, locally adapted landraces, and crop wild relatives which could be used to enrich cultivated gene pools. Although the ease of mobilization of favorable alleles into breeding materials is inversely related to the degree of adaptation, advances in genomics and molecular breeding technologies can accelerate the use of exotic germplasm for crop improvement ${ }^{25}$. However, access to novel allelic combinations available in the genebank collections requires thoughtful and renewed genotypic and phenotypic characterization of the materials ${ }^{6}$.

Allelic variation and genetic diversity. In the present study, a panel of 144 barley genotypes (80 tworowed and 64 six-rowed) including 69 landraces from various regions of Iran, and 50 landraces from other countries mainly from China and Egypt along with 9 advanced breeding lines and 16 commercial cultivars were genotyped using 149 SSR markers. This set of SSR markers amplified 691 alleles in the genotype under study and could provide a reasonable genotypic tool as a result of relatively high allele number, informativeness, and genomic coverage. The mean number of alleles/locus (4.64), gene diversity (0.55) and PIC (0.50) indicate a relatively high level of genetic variation in our study compared with some previous studies. An average of 3.20, 4.32, and 8.10 alleles/locus and the mean PIC of $0.38,0.52$, and 0.60 were reported in the analysis of diverse germplasms including wild and cultivated barley using SSR markers ${ }^{26-28}$.

The number of alleles/locus and PIC values have been suggested as a criterion to assess the level of genetic diversity in germplasm collections ${ }^{29}$. The presence of 17 SSR loci with PIC value of 0.80 or a higher and high number of alleles/locus could provide unique fingerprints for the studied barley genotypes and used for rapid analysis of genetic diversity and population structure in barley germplasm collections. A total of 691 polymorphic alleles detected in our study were enough to assess genetic relationships among barley landraces and cultivars. It was concluded that the presence of 350-550 alleles is enough for objective assessment of the genetic relationship between wheat accessions and it could be applicable for barley accessions as well ${ }^{30,31}$.

Overall genetic diversity in our study considering all types of materials was slightly lower compared with some studies carried out using barley landraces ${ }^{18,28}$. In our study, significant differences were observed between landraces and improved genotypes in number of alleles, number of effective alleles, number of private alleles, and gene diversity. On the other hand, the number of private alleles was 185 for the landraces while it was only 14 for cultivars and advanced breeding lines. It shows that modern breeding programs reduced the level of genetic variation in breeding materials. However, in our study, the number of landraces (119) was higher than that of cultivars and advanced breeding lines (25), but low level of genetic variation in the modern cultivars and breeding materials indicates the need of introducing new alleles from sources such as landraces and wild relatives to tackle climate change through plant breeding and better use of plant genetic resources. Compared with exotic landraces and "cultivars and advanced breeding lines", Iranian landraces had a higher level of gene diversity as revealed by $\mathrm{Na}, \mathrm{Ne}, \mathrm{He}$, and number of private alleles. Significant differentiation assessed by $\mathrm{F}_{\mathrm{ST}}(\mathrm{P}=0.001)$ was observed among the three groups. The number of private alleles in Iranian landraces (37 alleles at 29 loci) was also higher compared to exotic landraces (15 alleles at 14 loci) and "cultivars and advanced breeding lines" (14 alleles at 11 loci). Although Iranian landraces contained slightly more individuals compared with exotic landraces and "cultivars and advanced lines" (69 vs 50 and 25), this was consistent with the higher genetic variation in the Iranian landraces as revealed by number of alleles, number of effective alleles, gene diversity and Shannon's index (Table 2). The higher genetic diversity in Iranian landraces could be due to the fact that a second domestication event may have occurred in barley, possibly in Central Asia at the eastern edge of the Iranian Plateau, and that this separate origin may have been the progenitor of present-day barleys found in East and South Asia ${ }^{32,33}$.

Informative markers. Among the SSR loci with specific alleles in Iranian barley landraces, the following markers were associated with QTLs for malting quality, disease resistance, agronomic and physiological traits as reported by previous studies; Bmac209 (barley scald) ${ }^{34}$; Bmag345 (malting quality: hot water extract, diastatic power, alpha-amylase activity and free alpha-amino acid) ${ }^{35}$; Bmag382 (malting quality: hot water extract, grain protein content) ${ }^{36}$; Bmag518 (flag leaf physiological traits (intercellular $\mathrm{CO}_{2}$ concentration) ${ }^{37}$, chlorophyll content $^{38}$, septoria speckled leaf blotch ${ }^{39}$, plump grain and 1000 grain weight ${ }^{40}$ ); Bmag740 (adult spot blotch 
and net type net blotch ${ }^{39}$ and days to maturity ${ }^{41}$ ); Bmag751 (carbon isotope discrimination and grain yield ${ }^{41}$ ); EBmac541 (dehydration gene for drought tolerance ${ }^{42}$ ); GBM1482 (lodging and lodging components ${ }^{43}$; GBMS183 (plant height and spike number per plant); GBMS141 (Endosperm hardness ${ }^{40}$ ); GMS89 (grain yield ${ }^{26}$ ); HVM40 (nitrate accumulation ${ }^{44}$, days to heading ${ }^{26}$ ) and HVM74 (major grain protein, soluble $\alpha-\mathrm{NH} 2$ and grain protein concentration $^{44}$. Assessment of group-specific alleles across the genome in plant germplasms should identify both the regions of the genome that should be conserved and the regions of the genome where there are opportunities to introgress new allelic diversity in the breeding materials without disrupting desirable gene complex.

Population structure. We employed various statistical approaches to ensure the reliability of the inferences made regarding population structure in the collection. Although the results of model-based clustering were further ascertained by the results from the distance-based cluster analysis (Figs. 1, 2, 3) and PCoA (Figs. 4, 5, 6), the dendrograms resulted from NJ clustering were mostly in accord with the model-based clustering inferred groups. In the PCoA bi-plots, overlapping was observed among some of the inferred groups and represented a blurred distinction among the groups. Especially cluster I and III and cluster II and IV show some overlap. The row type in barley is an important determinant of the population structure ${ }^{45}$. In our studies, with $\mathrm{K}=2$, two- and six-rowed genotypes were assigned into distinct sub-populations. With an optimal number of clusters $\mathrm{K}=4$, except cluster III, two- and six-rowed genotypes were grouped separately. Cluster I, II, and IV consisted of $89 \%$, $88 \%$ and $74 \%$ six-row, two-row, and two-row accessions, respectively. Cluster III is structured by $45 \%$ two-row and 55\% six-row accessions. Our observations showed that Iranian barley landraces are different in comparison to the exotic landraces and mostly grouped separately. This could be due to the different evolutionary and domestication history of barley from Iran offers a plausible explanation for the observed differences ${ }^{32,33}$.

To further explore the genetic diversity and relationships among the clusters and within the clusters, allelic pattern and various diversity statistics were assessed for each of the STRUCTURE inferred clusters (Table 2). The cluster III (a relatively mixed group with two- and six-row accessions consisted of cultivars, advanced breeding lines and some landraces from various countries) with a higher number of member among clusters (42) had maximum mean number of alleles, number of effective alleles, gene diversity and Shannon index (4.29, 3.09, 0.57 and 1.09). Group-specific rare alleles detected in cluster III was also high compared with the others, emphasizing the presence of a higher diversity in this group. A total of 52 group-specific alleles at 36 loci were identified in cluster III. The number of group-specific alleles for cluster I was 19 alleles at 18 gSSR loci, one for group IV and no specific alleles were detected for cluster II. The higher heterogeneity in cluster III may be due to ecogeographical diversity and multiple barley domestication sites apart from Fertile Crescent. Comparison of the genetic structure of Western and Eastern cultivated barleys proposed a secondary domestication site of barley somewhere 1500-3000 km east of Fertile Crescent and found greater allelic differences between these groups $\mathrm{s}^{32}$.

\section{Conclusion}

In the present study, we utilized microsatellite markers to assess the effect of breeding history, origin, and growth type on genetic diversity and population structure of barley genotypes. Assigning of Iranian landraces, exotic landraces and "varieties and advanced breeding lines" into separate groups based on both gSSR and EST-SSt data could be due to their different evolutionary, domestication, and breeding history. The higher genetic diversity in Iranian landraces revealed by high allelic diversity and private alleles number could be due to the fact that a second domestication event may have occurred in barley, possibly in Central Asia at the eastern edge of the Iranian Plateau. The allelic diversity presented in the studied collection, especially in Iranian landraces was found to be correlated with population structure, domestication, and eco-geographical factors. The high allelic richness in the studied set of barley genotype as revealed by genetic and statistical analyses provides insights into the available diversity and allows construction of core groups based on maximizing allelic diversity for use in Iranian barley breeding programs. The Iranian landrace panel comprised lines that were well distributed across all eco-geographical regions with different climatic regimes which could be used for introgression of favorite alleles into breeding lines.

\section{Materials and methods}

Plant materials. A set of 144 barley genotypes (80 two-rowed and 64 six-rowed) including 69 landraces from various regions of Iran, 23 from China, 12 from Egypt and 15 from the USA, England, India, Pakistan and Algeria along with 9 advanced breeding lines and 16 commercial varieties was used. Out of 144 genotypes, 61, 69 , and 14 were spring, winter, and facultative growth habits, respectively. The majority of six-row and two-row barley genotype were winter types $(88.8 \%, 70.0 \%$, respectively) (Table 5$)$.

Genomic and EST-SSR genotyping. Genomic DNA was extracted from bulked fresh leaf samples of each genotype using the CTAB method ${ }^{46}$. Although the genotypes used in our study are homozygous lines, a pool of leaves from 15 plants of each genotype was used for DNA extraction to provide a reliable measure of the possible genetic heterogeneity within each genotype ${ }^{47,48}$. The $0.8 \%(\mathrm{w} / \mathrm{v})$ agarose gel electrophoresis and spectrophotometer were used to examine the quality and quantity of the DNA samples, respectively. Each genotype was analyzed using a set 77 and 72 polymorphic EST-SSR and gSSR markers, respectively distributed on seven chromosomes of barley. Bin locations of the markers were adapted from Grain Genes Map Data Report: Barley, Steptoe $\times$ Morex, SSR (https://wheat.pw.usda.gov/cgi-bin/graingenes/report). The PCR reaction mixture was prepared in a final volume of $10 \mu \mathrm{L}$ containing 40 ng template DNA, $1 \times$ PCR buffer, 0.025 units Taq DNA polymerase (Sinagene, Iran), $0.2 \mathrm{mmol}$ dNTPs, and $0.8 \mathrm{pmol}$ forward and reverse primers. Amplifications were performed under the following conditions: $4 \mathrm{~min}$ at $94^{\circ} \mathrm{C}$, followed by 35 cycles at $94{ }^{\circ} \mathrm{C}$ for $1 \mathrm{~min}$, primer annealing at $58-68{ }^{\circ} \mathrm{C}$ for $1 \mathrm{~min}$ depending on primers and $72{ }^{\circ} \mathrm{C}$ for $1 \mathrm{~min}$, and a final extension at $72^{\circ} \mathrm{C}$ for 
7 min. A Gel-Scan 3000 electrophoresis system (a real-time laser scanning electrophoresis system, Corbett Co.) based on $4 \%$ ultra-thin $(0.2 \mathrm{~mm})$ non-denature polyacrylamide gel stained by ethidium bromide was used to visualize PCR products.

Statistical analysis. Number of allele (Na), number of effective allele (Ne), major allele frequency (MAF), Shannon's index (I), gene diversity $(\mathrm{He})$ and polymorphic information content (PIC) were determined for all the analyzed markers across the total population as well as landraces and "varieties and advanced breeding lines" using PowerMarker version $3.25^{49}$ and GenAlEx 6.5 software ${ }^{50}$. Polymorphism Information Content (PIC) values were determined as $P I C=1-\sum p_{i}^{2}-2 \sum p_{i}^{2} p_{j}^{251}$. Gene diversity was calculated as $\mathrm{He}=1-\sum p_{i}^{252}$. Shannon's information index was estimated as $I=-\sum p_{i} \ln p_{i}$, where $p_{i}$ and $p_{j}$ are the frequencies of the $i$ th and $j$ th alleles of a given locus, respectively.

Population structure in a collection of 144 barley genotypes including Iranian and exotic landraces, advanced breeding lines, and cultivars was assessed by two statistical methods. The model-based clustering implemented in STRUCTURE 2.3.4 ${ }^{53}$ was performed by running 100,000 Markov chain Monte Carlo (MCMC) iterations after a burn-in of 100,000 replicates with 5 independent runs per K ranging from 1 to 10 , using the admixture model with correlated allele frequencies, which estimates fractions of individual genomes that belong to different ancestry groups. The optimal number of cluster $(\mathrm{K})$ was determined by calculating the mean posterior probability for each $\mathrm{K}$ value, $\mathrm{LnP}(\mathrm{D})$, which is based on the estimated maximum log-likelihood values ${ }^{53}$. The $\Delta \mathrm{K}$ values (the rate of change in the log probability of data between successive K values) was also calculated as suggested by ${ }^{54}$ using STRUCTURE-HARVESTER, version 0.6.9455.

We used principal coordinate analysis (PCoA) for genetic differentiation between two- and six-row genotypes, among spring, winter, and facultative genotypes as well as Iranian landraces, exotics landraces, and "varieties and advanced breeding lines. The PCoA was performed on GenAIEx 6.501 software ${ }^{27}$. Finally, the unrooted neighbor-joining (N-J) clustering algorithm under the Reynold 1983 distance coefficient was applied using the software PowerMarker $3.25^{26}$ to investigate the relationship of barley accessions.

A hierarchical analysis of molecular variance (AMOVA) implemented in GenAlex $6.501^{27}$ was used the partition of the observed molecular variation among and within the three clusters inferred using STRUCTURE and NJ cluster analyses corresponding to Iranian landraces, exotic landraces and "cultivars and advance breeding lines". The genetic parameters including the number of a different allele with a frequency $\geq 0.05$, the number of effective alleles, Shannon's index (I), and unbiased expected heterozygosity $(\mathrm{uHe}=(2 \mathrm{~N} /(2 \mathrm{~N}-1)) \times \mathrm{He})$ were estimated for each cluster, where $\mathrm{N}$ is group size.

\section{Data availability}

The data are available on request.

Received: 29 July 2019; Accepted: 13 October 2020

Published online: 05 November 2020

\section{References}

1. Zohary, D. \& Hopf, M. Domestication of Plants in Old World: The Origin and Spread of Cultivated Plants in West Asia, Europe and the Nile Valley 3rd edn. (Clarendon Press, Oxford, 1993).

2. Harlan, J. R. \& Zohary, D. Distribution of wild wheats and barley. Science 153, 1074-1080 (1966).

3. Molina-Cano, J. L. et al. Chloroplast DNA microsatellite analysis supports a polyphyletic origin for barley. Theor. Appl. Genet. 110, 613-619 (2005).

4. Rodriguez, M., Rau, D. \& Attene, G. Genotype by environment interactions in barley (Hordeum vulgare L.): different responses of landraces, recombinant inbred lines and varieties to Mediterranean environment. Euphytica 163, 231-247 (2008).

5. Bockelman, H. E. \& Valkoun, J. Barley germplasm conservation and resources. In Barley: Production, Improvement, and Uses (ed. Ullrich, S. E.) 144-159 (Wiley- Blackwell, New York, 2011).

6. Muñoz-Amatriaín, M. et al. The USDA barley core collection: Genetic diversity, population structure, and potential for genomewide association studies. PLOS ONE 9, e94688. https://doi.org/10.1371/journal.pone.0094688 (2014).

7. Harlan, J. R. Barley. In Evolution of Crop Plants (eds Smartt, J. \& Simmonds, N. W.) 140-146 (Longman, London, 1995).

8. Brush, S. B. The issues of in situ conservation of crop genetic resources. In Genes in the Field. On Farm Conservation of Crop Diversity (ed. Brush, S. B.) 3-26 (IPGRI/IDRC/Lewis Publishers, Boca Raton, 2000).

9. Brown, A. H. D. The genetic structure of crop landraces and the challenge to conserve them in situ on farms. In Genes in the Field. On Farm Conservation of Crop Diversity (ed. Brush, S. B.) 19-48 (IPGRI/IDRC/Lewis Publishers, Boca Raton, 2000).

10. Rodriguez, M. et al. Genetic structure and linkage disequilibrium in landrace populations of barley in Sardinia. Theor. Appl. Genet. 125, 171-184 (2012).

11. Fischbeck, G. Diversification through breeding. In Diversity in barley (Hordeum vulgare) (eds von Bothmer, R. et al.) 29-52 (Elsevier Science B.V., Amsterdam, 2003).

12. Yahiaoui, S. et al. Spanish barley landraces outperform modern cultivars at low-productivity sites. Plant Breed. 133, 218-226 (2014).

13. Jones, H. et al. Evolutionary history of barley cultivation in Europe revealed by genetic analysis of extant landraces. BMC Evol. Biol. 11, 320. https://doi.org/10.1186/1471-2148-11-320 (2011).

14. Jones, H. et al. Approaches and constraints of using existing landraces and extant plant material to understand agricultural spread in prehistory. Plant Genet. Resour. Charact. Util. 6, 98-112 (2008).

15. Ceccarelli, S. \& Grando, S. Barley landraces from the Fertile Crescent: a lesson for plant breeders. In Genes in the Field. On Farm Conservation of Crop Diversity (ed. Brush, S. B.) 51-75 (IPGRI/IDRC/Lewis Publishers, Boca Raton, 2000).

16. Comadran, J. et al. Patterns of polymorphism and linkage disequilibrium in cultivated barley. Theor. Appl. Genet. 122, 523-531 (2011).

17. Malysheva-Otto, L. V., Ganal, M. W. \& Röder, M. S. Analysis of molecular diversity, population structure and linkage disequilibrium in a worldwide survey of cultivated barley germplasm (Hordeumvulgare L.). BMC Genet. 7, 6. https://doi.org/10.1186/1471-21567-6 (2006).

18. Bellucci, E. et al. Population structure of barley landrace populations and gene-flow with modern varieties. PLoS ONE 8(12), e83891. https://doi.org/10.1371/journal.pone.0083891 (2013). 
19. Pasam, R. K. et al. Genetic diversity and population structure in a Legacy collection of spring barley landraces adapted to a wide range of climates. PLoS ONE 9, e116164. https://doi.org/10.1371/journal.pone.0116164 (2014).

20. Russell, J. et al. Genetic diversity and ecological niche modelling of wild Barley: refugia, large-scale post-LGM range expansion and limited mid-future climate threats?. PLoS ONE 9, e86021. https://doi.org/10.1371/journal.pone.0086021 (2014).

21. Palumbo, F., Galla, G. \& Barcaccia, G. Developing a molecular identification assay of old landraces for the genetic authentication of typical agro-food products: the case study of the Barley 'Agordino'. Food Technol. Biotechnol. 55, 29-39 (2017).

22. Hasan, M., Odat, N., Qrunfleh, I., Shakhatreh, Y. \& Saifan, S. Microsatellite analysis of genetic diversity and population structure of Jordanian barley (Hordeum vulgare L.) reveals genetic polymorphism and divergence associated with inflorescence type. Res. Crops 19, 86-96 (2018).

23. Caldwell, K. S., Russell, J., Langridge, P. \& Powell, W. Extreme population dependent linkage disequilibrium detected in an inbreeding plant species, Hordeum vulgare. Genetics 172, 557-567 (2006).

24. Tester, M. \& Langridge, P. Breeding technologies to increase crop production in a changing world. Science 327, 818-822 (2010).

25. Muñoz-Amatriaín, M., Cuesta-Marcos, A., Hayes, P. M. \& Muehlbauer, G. J. Barley genetic variation: implications for crop improvement. Brief. Funct. Genomics 13, 341-350. https://doi.org/10.1093/bfgp/elu006 (2014).

26. Pillen, K., Zacharias, A. \& Léon, J. Comparative AB-QTL analysis in barley using a single exotic donor of Hordeum vulgare ssp. spontaneum. Theor. Appl. Genet. 108, 1591-1601 (2004).

27. Salem, K. F. M., Varshney, R. K., Roder, M. S. \& Borner, A. EST-SSR based estimates on functional genetic variation in a barley (Hordeum vulgare L.) collection from Egypt. Genet. Resour. Crop Evol. 57, 515-521 (2010).

28. Castillo, A., Dorado, G., Feuillet, C., Sourdille, P. \& Hernandez, P. Genetic structure and ecogeographical adaptation in wild barley (Hordeum chilense Roemer et Schultes) as revealed by microsatellite markers. BMC Plant Biol. 10, 1-13 (2010).

29. Hao, C. Y. et al. Genetic diversity and core collection evaluations in common wheat germplasm from the Northwestern spring wheat region in China. Mol. Breed. 17, 69-77 (2006).

30. Zhang, X. Y. et al. An estimation of the minimum number of SSR alleles needed to reveal genetic relationships in wheat varieties. I. Information from large-scale planted varieties and cornerstone breeding parents in Chinese wheat improvement and production. Theor. Appl. Genet. 106, 112-117 (2002).

31. You, G. X., Zhang, X. Y. \& Wang, L. F. An estimation of the minimum number of SSR loci needed to reveal genetic relationships in wheat varieties: Information from 96 random accessions with maximized genetic diversity. Mol. Breed. 14, 397-406 (2004).

32. Morrell, P. L. \& Clegg, M. T. Genetic evidence for a second domestication of barley (Hordeum vulgare) east of the Fertile Crescent. Proc. Natl. Acad. Sci. U.S.A. 104, 3289-3294 (2007).

33. Saisho, D. \& Purugganan, M. D. Molecular phylogeography of domesticated barley traces expansion of agriculture in the old world. Genetics 177, 1765-1776 (2007).

34. Grønnerød, S. et al. Genetic analysis of resistance to barley scald (Rhynchosporium secalis) in the Ethiopian line 'Abyssinian' (CI668). Euphytica 126, 235-250 (2002).

35. Panozzo, J. F. et al. QTL analysis of malting quality traits in two barley populations. Aust. J. Agric. Res. 58, 858-866 (2007).

36. Laidó, G. et al. QTL alleles from a winter feed type can improve malting quality in barley. Plant Breed. 128, 598-605 (2009).

37. Liu, L., Sun, G., Ren, X., Li, C. \& Sun, D. Identification of QTL underlying physiological and morphological traits of flag leaf in barley. BMC Genet. 16, 29. https://doi.org/10.1186/s12863-015-0187-y (2015).

38. Xue, D. et al. QTL analysis of flag leaf in barley (Hordeum vulgare L.) for morphological traits and chlorophyll content. J. Zhejiang Univ. Sci. B 9, 938-943 (2008).

39. Yun, S. J. et al. Validation of quantitative trait loci for multiple disease resistance in barley using advanced backcross lines developed with a wild barley. Crop Sci. 46, 1179-1186 (2006).

40. Walker, C. K. et al. Chromosomal loci associated with endosperm hardness in a malting barley cross. Theor. Appl. Genet. 122, 151-162 (2010).

41. Chen, J., Chang, S. X. \& Anyia, A. O. Quantitative trait loci for water-use efficiency in barley (Hordeum vulgare L.) measured by carbon isotope discrimination under rain-fed conditions on the Canadian Prairies. Theor. Appl. Genet. 125, 71-90 (2012).

42. Suprunova, T. et al. Identification of a novel gene (Hsdr4) involved in water stress tolerance in wild barley. Plant Mol. Biol. 64, 17-34 (2007).

43. Chen, W. Y. et al. Genetic relationship between lodging and lodging components in barley (Hordeum vulgare) based on unconditional and conditional quantitative trait locus analyses. Genet. Mol. Res. 13, 1909-1925 (2014).

44. Mickelson, S. et al. Mapping of QTL associated with nitrogen storage and remobilization in barley (Hordeum vulgare L.) leaves. J. Exp. Biol. 54, 801-812 (2003).

45. Haseneyer, G. et al. Population structure and phenotypic variation of a spring barley world collection set up for association studies. Plant Breed. 129, 271-279 (2010).

46. Saghai Maroof, M. A., Biyashev, R. M., Yang, G. P., Zhang, Q. \& Allard, R. W. Extraordinary polymorphic microsatellite DNA in barley: species diversity chromosomal locations and population dynamics. Proc. Natl. Acad. Sci. U.S.A. 91, 5466-5470 (1994).

47. Gilbert, J. E., Lewis, R. V., Wilkinson, M. J. \& Caligari, P. D. S. Developing an appropriate strategy to assess genetic variability in plant germplasm collections. Theor. Appl. Genet. 98, 1125-1131 (1999).

48. Dreisigacker, S. et al. SSR and pedigree analyses of genetic diversity among CIMMYT wheat lines targeted to different megaenvironments. Crop Sci. 44, 381-388 (2004).

49. Liu, K. \& Muse, S. V. Power Marker: integrated analysis environment for genetic marker data. Bioinformatics 21, 2118-2119 (2005).

50. Peakall, R. \& Smouse, P. E. GenAlEx 6.5: genetic analysis in Excel. Population genetic software for teaching and research-an update. Bioinformatics 28, 2537-2539 (2012).

51. Botstein, D., White, R. L., Skolnick, M. \& Davis, R. W. Construction of a genetic linkage map in man using restriction fragment length polymorphisms. Am. J. Hum. Genet. 32, 314-331 (1980).

52. Nei, M. Estimation of average heterozygosity and genetic distance from a small number of individuals. Genetics 89, 583-590 (1978).

53. Pritchard, J. K., Stephens, M. \& Donnelly, P. Inference of population structure using multilocus accession data. Genetics $\mathbf{1 5 5}$, 945-959 (2000).

54. Evanno, G., Regnaut, S. \& Goudet, J. Detecting the number of clusters of individuals using the software STRUCTURE: a simulation study. Mol. Ecol. 14, 2611-2620 (2005).

55. Earl, D. A. \& Vonholdt, B. M. STRUCTURE HARVESTER: a website and program for visualizing STRUCTURE output and implementing the Evanno method. Conserv. Genet. Resour. 4, 359-361 (2012).

\section{Acknowledgements}

This study was supported by the Center of Excellence in Cereal Molecular Breeding, University of Tabriz, Iran, and research grant 27/3440-1 form the University of Tabriz, Iran.

\section{Author contributions}

S.A.M. designed the experiment, analyzed the data, and wrote the manuscript, N.A.S. did molecular analyses and B.S. provided the plant materials. All authors reviewed the manuscript. 


\section{Competing interests}

The authors declare no competing interests.

\section{Additional information}

Correspondence and requests for materials should be addressed to S.A.M.

Reprints and permissions information is available at www.nature.com/reprints.

Publisher's note Springer Nature remains neutral with regard to jurisdictional claims in published maps and institutional affiliations.

(c) (i) Open Access This article is licensed under a Creative Commons Attribution 4.0 International License, which permits use, sharing, adaptation, distribution and reproduction in any medium or format, as long as you give appropriate credit to the original author(s) and the source, provide a link to the Creative Commons licence, and indicate if changes were made. The images or other third party material in this article are included in the article's Creative Commons licence, unless indicated otherwise in a credit line to the material. If material is not included in the article's Creative Commons licence and your intended use is not permitted by statutory regulation or exceeds the permitted use, you will need to obtain permission directly from the copyright holder. To view a copy of this licence, visit http://creativecommons.org/licenses/by/4.0/.

(C) The Author(s) 2020 